\title{
100 years of IJPH: looking back and ahead
}

\author{
Anke Berger $^{1} \cdot$ Andrea Madarasova Geckova $^{2}$ - Olaf von dem Knesebeck ${ }^{3} \cdot$ Nino Künzli ${ }^{1,4}$
}

Published online: 9 November 2020

(C) Swiss School of Public Health (SSPH+) 2020

By the end of 2020, the IJPH will turn 100 years old! Thus, IJPH is far older than its proud owner, the Swiss School of Public Health $(\mathrm{SSPH}+)$. The traces of the journal go back even further to 120 years when we account for a public health book series as the first predecessor of IJPH (Ackermann-Liebrich 2006). There are not many society journals with such a long tradition in the field of public health (Paradis 2009).

A relevant success factor of a journal is impact. Although the impact factor is meaningless in assessing any given article (DORA 2013), researchers still prefer high impact journals for their articles. The IJPH 5-year IF reached 3.0 twice so far, and the 2-year IF fluctuates between 2.4 and 2.7, placing IJPH in the top quartile rank in 8 of the last 10 years. We would be delighted to see the impact factor increase. On the other hand, we continue to publish research from lower-income countries. Such research is often of high local relevance but gets less often cited during the 2 year relevant for the impact factor. More importantly, IJPH has a wide scientific audience, reflected in an average citation per article of 12.6. But does IJPH have any impact on public health? We wished to have indicators at hand to measure the ultimate impact of the published science given that IJPH does want to contribute to a healthier world.

This editorial marks the 100th anniversary of the International Journal of Public Health.

Anke Berger

anke.berger@swisstph.ch

1 Swiss Tropical and Public Health Institute, Basel, Switzerland

2 Department of Health Psychology and Research Methodology, Faculty of Medicine, Pavel Jozef Safarik University, Kosice, Slovakia

3 Institute of Medical Sociology, University Medical Center Hamburg-Eppendorf, Hamburg, Germany

4 Swiss School of Public Health, Zurich, Switzerland
Expanding the geographical outreach of IJPH was a major success in the past 10 years. With Andrea Madarasova Geckova joining the board (Kohlmann 2007), IJPH began promoting the interesting research in the former Soviet countries in Central and Eastern Europe (CEE) that was not adequately represented in Western public health journals. IJPH provided individual editorial and writing support. Since 2010, $8 \%(n=166)$ of the articles in IJPH are from CEE authors and the average citation rates per article (9.0) almost reach IJPH average (10.7) in this period. The impact of special issues from CEE countries regularly exceed the IJPH impact factors. The diversity and originality of topics that CEE authors contributed to IJPH are inspiring.

Since 2014, we promote articles from Africa where precarious conditions for researchers are a strong barrier to science and publishing (Waiswa 2015). Strong ties to the Swiss Tropical Public Health Institute and the CARTA network resulted in submissions from Africa to almost triple since 2014. We just published the first special issue "Sexual and reproductive health of young people-focus Africa" (Merten et al. 2020). Since 2016, our senior editor from Colombia extremely well promotes the IJPH in Latin America (LATAM) by connecting calls for papers to local public health conferences and running best-article awards (e.g., Méndez and Osorio 2017). Within 4 years, the number of submissions from LATAM more than tripled. The IJPH is also very popular in the Eastern Mediterranean Region and in South East Asia, and we welcome research from Western Pacific.

The most important factor for any success of IJPH in the past and in the future is the commitment of idealistic scientists. The first editor-in-chief led the journal singlehandedly for 34 years (Ruckstuhl 2020). Today, due to massive increase in submissions and complex tasks, leading the IJPH now is true teamwork of three chief editors (Kohlmann et al 2012). Shared leadership in combination with the strong strategic support from our excellent senior editors has proven efficient. IJPH would not be anywhere without the commitment of associate editors. We constantly work to keep the team balanced in expertise, origin 
and gender. Currently, 49 editors from 18 countries support the IJPH and $41 \%$ are female. We appreciate their broad and complex expertise as public health research has become more interdisciplinary and inter-sectoral. A unique feature of IJPH is our training of future editors. Since 2015, we teach early career scientists in journal editing in a blended learning course, and we offer $\mathrm{PhD}$ students options to get trained and act as editors and reviewers of the Young Researcher Editorials_-all written by $\mathrm{PhD}$ students from around the world (Berger and Künzli 2018).

IJPH is just making a big step into the future by publishing open access from January 2021 onwards (Tonia 2020). The increasing support of research funders and research institutions for the gold open access model made the decision easy finally, although risks remain for a single self-financing society-owned journal. After thorough assessment of six candidates and two finalists, we selected Frontiers as the new publisher of IJPH. We share commitment and plans to advance IJPH. Our next common step will be to significantly increase the speed of the peer review in IJPH.

Finances are a key factor for an independent society journal. For very long, IJPH's for-profit publisher did not share revenues; thus, IJPH had to collect funds from society membership fees or university contributions. With SSPH + taking over the ownership in 2010, this ill-defined traditional business model accepted by many society journals was rightfully put in question. Negotiations with several publishers finally resulted in a contract, as of 2013, with Springer Nature fully funding the IJPH editorial office through shared revenues. This financial independence prepared the floor for successful negotiations in the move toward open access. IJPH, thus, remains an independent and self-funded society journal to strengthen public health science publishing from all continents.

Will the IJPH survive as a society journal in the changing publishing industry that seems to favor the big publishers so much with their mass production of articles? We are confident it will. IJPH is in a sustainable position. The history of IJPH demonstrates that committed editors can cope with any change and make change a success factor. We do not know if there will be journals 100 years from now, but we believe that there will be a demand for good public health science communication based on peer review and the work of dedicated scientific editors.

Acknowledgements On behalf of SSPH+ and IJPH, we thank the Springer Nature New York team for the support and fruitful cooperation 2013-2020, and the Institute of Social and Preventive Medicine, University of Bern (2000-2017) and the Swiss Tropical and Public Health Institute, Basel (since 2017), for hosting the IJPH Editorial Office.

\section{References}

Ackermann-Liebrich U (2006) 50 (or 106?) years Sozial- und Präventivmedizin (Social and Preventive Medicine). Soz Praventiv Med 51:69-73

Berger A, Künzli N (2018) Welcome to the third training pillar of IJPH: Young Researcher Editorials. Int J Public Health 63, 1009-1010. 10.1007/s00038-018-1159-6

DORA The San Francisco Declaration on Research Assessment (2013) https://sfdora.org/read/, Accessed 01 Sep 2020

Kohlmann T (2007) Welcome note from the new Editor-in-Chief. Int J Public Health 52:123-124. https://doi.org/10.1007/s00038007-7031-8)

Kohlmann T, Künzli N, Madarasova Geckova A (2012) Continuity and change at an international journal. Int J Public Health 57:1

Méndez F, Osorio L (2017) Development and health: keeping hope alive in the midst of irrationality. Int $\mathrm{J}$ Public Health 62:175-176. https://doi.org/10.1007/s00038-016-0892-y

Merten S, Mlotshwa L, Schwarz J (2020) Youth, sexuality, gender, and health: dealing with a social phenomenon. Int J Public Health 65:375-376. https://doi.org/10.1007/s00038-020-01392-5

Paradis G (2009) 100 years of publishing public health science. Revue Canadienne de Santé Publique 100(1):4

Ruckstuhl B (2020) The IJPH turns 100 years old: let's look back! Int J Public Health 65:705-707

Tonia T (2020) IJPH to soon become open access! IJPH Blog post. https://blogs.springer.com/ijph/announcements/ijph-to-soonbecome-open-access/, Accessed 01 Sep 2020

Waiswa P (2015) Productive global health research from Africa: it takes more. Int J Public Health 60:755-756

Publisher's Note Springer Nature remains neutral with regard to jurisdictional claims in published maps and institutional affiliations. 